Check for updates

Cite this: RSC Adv., 2017, 7, 31779

\title{
Synthesis and mechanism study of gelatin grafted acetone formaldehyde sulphonates as oil-well cement dispersant
}

\begin{abstract}
Chengwen Wang, Renzhou Meng, (D)* Ruihe Wang and Zhonghou Shen
A novel dispersant, gelatin grafted acetone formaldehyde sulphonates (GAFS), was synthesized for oil-well cement. GAFS was synthesized by aldehyde ketone addition reaction, hydroxyl condensation reaction and Mannich amine methylation reaction, using gelatin, acetone, formaldehyde and sodium metabisulfite as the base materials. Functional groups and the molecular structure of GAFS were characterized by Fourier transform infrared spectroscopy. Evaluating experiments of GAFS mechanical properties and application performances were conducted. The results show that GAFS can be adsorbed on the cement particles tightly because of the electrostatic forces, and the adsorption amount of GAFS on cement particle surfaces is great. The adsorption of GAFS is spontaneous, and adsorption strength between GAFS and cement particles is high. GAFS can generate a great potential energy barrier, resulting in excellent dispersion performance. The adsorption of GAFS on cement particles is physical adsorption. Consequently, GAFS hardly influences the hydration reaction and imposes no retarding effect on the cement.
\end{abstract}

Received 28th March 2017

Accepted 13th June 2017

DOI: $10.1039 / \mathrm{c} 7 \mathrm{ra03602g}$

rsc.li/rsc-advances acid also have good dispersing effect. Although many types of dispersants have been developed and successfully applied to well cementing operations, there are also some side effects of these dispersants, for example, poor biodegradability (e.g., polynaphthalene sulphonate), retarding effect under low temperature (e.g., lignosulphonate, citric acid), high-cost (e.g., polystyrene sulphonate). With the petroleum industry paying more attention to offshore petroleum development, issues of environmental protection and low temperature have become increasingly prominent. ${ }^{8,9}$ Consequently, the development of novel cement dispersant with excellent dispersing performance, biodegradability and less retarding effect has become a key, as well as challenging task.

Gelatin is a kind natural protein substance formed by various amino acids which are mutually connected by peptide bond, with free function groups on the main chain. The gelatin contains hydrolysable groups hydroxide radical, carboxyl and amidogen so that it can be easily biodegraded. ${ }^{\mathbf{1 0 , 1 1}}$ In this paper, a novel dispersant, gelatin grafted acetone formaldehyde sulphonates (GAFS), was synthesized for oil well cement, using gelatin, acetone, formaldehyde and sodium metabisulfite as the base materials. The adsorption performance and dispersing performance were analyzed quantitatively. The adsorption thermodynamics and dispersing mechanism were studied. Meanwhile, the influence of GAFS to the compressive strength was evaluated and the micro structure of cement matrix with GAFS was analyzed by scanning electron microscope (SEM). 


\section{Experimental}

\section{Materials}

Formaldehyde (37 wt $\%$ aqueous solution), sodium pyrosulfite (99.0\% purity), acetone (99.0\% purity), hydrochloric acid (36 wt\% aqueous solution) and solid sodium hydroxide all were purchased from Sinopharm Group Company Limited. Gelatin are purchased from Xiamen Huaxuan company.

An API class-G oil well cement corresponding to API Specification 10A was used, which was purchased from Sichuan Jiahua cement company.

\section{Synthesis and characterization}

The gelatin grafted acetone formaldehyde sulphonates (GAFS) is synthesized and the molecular weight was measured by gel permeation chromatography based on a procedure previously reported. ${ }^{12}$ The structure of GAFS was characterized by Fourier transform infrared spectroscopy (FTIR). The FTIR spectra in the range of $4000-400 \mathrm{~cm}^{-1}$ was recorded on a spectrophotometer (thermo Nicolet NEXUS spectrophotometer).

\section{Adsorption measurement}

Cement slurry was prepared by sufficiently blending $10 \mathrm{~g}$ class$\mathrm{G}$ cement and $20 \mathrm{~mL}$ aqueous solution with different concentration GAFS. Then the cement slurry was put in the electrothermostat at different temperature for $30 \mathrm{~min}$ until the system achieved the adsorption equilibrium. The upper liquid portion was filtrated and poured into the centrifugal tube for separation by the centrifuge (Rev. $12000 \mathrm{rpm}$ ) for $5 \mathrm{~min}$. The total content of organic carbon (TOC) of the supernatant was determined by Vario EL III instrument (Elementary Company, Germany). From the difference between the total amount of dispersant reference sample and the TOC content of the supernatant, the adsorbed amount of dispersant was computed. ${ }^{13}$

The adsorbent layer thickness of GAFS on the cement particles surface was tested by photoelectron spectroscopy. Carbon is the characteristic element to distinguish the dispersant and cement. The absorption peak of $\mathrm{C}_{12}$ of cement particles without GAFS was tested. After cement particles adsorbed GAFS, the absorption peaks of $\mathrm{C}_{12}$ of cement particles at different etched depths were tested. The etched depth, at which the absorption peaks of $\mathrm{C}_{12}$ of cement particles after adsorbing GAFS is equal to it before adsorbing GAFS, is the adsorbent layer thickness.

\section{Zeta potential measurement}

The cement slurry was prepared with the water/cement ratio being 2:1 to ensure that cement particles can disperse adequately, and dispersant product with a given mass fraction (\% bwoc) was added. The zeta potential of cement slurry was measured by ZetaProbe Analyzer (Colloidal Dynamics Company, USA). The average value of the zeta potential, which was measured three times, is adopted in this study.

\section{Performance tests in class-G oil well cement}

The cement slurry was prepared with the water/cement ratio being 0.44 , and dispersant product with a given mass fraction (\% bwoc) was added. According to the standard "API RP10B-2$2013 ",{ }^{14}$ the rheological property of the cement slurry was tested by ZNN-D6 rotary viscometer (Qingdao Haitongda Instrument Factory, China) while the compressive strength was tested by NYL-300 compression testing machine (Wuxi Building Materials Equipment Factory, China). The liquidity index $n$, consistency coefficient $k$ and yield value $\tau_{0}$ can be calculated by eqn (1)-(3):

$$
\begin{gathered}
n=2.096 \lg \left(\frac{\theta_{300}}{\theta_{100}}\right) \\
k=\frac{0.511 \theta_{300}}{511^{n}} \\
\tau_{0}=0.511\left(2 \theta_{300}-\theta_{600}\right)
\end{gathered}
$$

The $n$ and $k$ can be used to measure the liquidity and thickness of cement. The $\tau_{0}$ presents the critical stress which prevent the flow of plastic fluids. The $\theta_{100}, \theta_{300}$ and $\theta_{600}$ present the viscometer reading at $100 \mathrm{rpm}, 300 \mathrm{rpm}$ and $600 \mathrm{rpm}$.

The static stability of cement slurry with GAFS was studied by this test. Firstly, the slurry was prepared at a water/cement ratio of 0.44 . Then the slurry was poured into a sedimentation tube with an inner diameter of $25 \mathrm{~mm}$ while a tube length of 200 $\mathrm{mm}$. After being cured for $24 \mathrm{~h}$ at room temperature, the cement sample was taken out from the sedimentation tube and immersed in water to prevent it from drying out. The sample was marked at $10 \mathrm{~mm}$ from bottom and top sides, and the middle section was gotten between two marks. Then the middle section was equally divided into 5 segments, and the density of these segments were tested by using drainage method.

Scanning electron microscope (SEM) is an effective means for analyzing the micro structure. The cement matrix sample piece was pasted to a copper sample holder with conductive adhesive, and gilt in vacuum, then observed under S4800 SEM (Hitachi, Japan) at an accelerating voltage of $5.0 \mathrm{kV}$.

\section{Results and discussion}

\section{Synthesis and characterization}

The synthesis process of GAFS, at first, proceeds by condensation reaction between formaldehyde and acetone, and addition reaction between acetone and sodium pyrosulfite, in the environment of $\mathrm{pH}=14$. Then, those reaction products are condensed with each other, forming sulfonated acetoneformaldehyde. The chemical reaction and molecular structure of sulfonated acetone-formaldehyde are shown in Fig. 1.

The molar ratio of formaldehyde/acetone should be in the range of 1.6-1.8 to ensure an overdose of acetone, by which the side reaction between formaldehyde and sodium pyrosulfite can be inhibited. When the molar ratio formaldehyde/acetone is high than 1.8, the dose of formaldehyde is excessive, and the excessive formaldehyde can continue to react with $\beta$-hydroxy 


$$
\begin{aligned}
& \stackrel{\stackrel{\mathrm{O}}{\mathrm{HCHO}}+\mathrm{CH}_{3} \mathrm{CCH}_{3}}{\stackrel{\mathrm{NaOH}}{\longrightarrow}} \stackrel{\stackrel{\mathrm{O}}{30-40^{\circ} \mathrm{C}}}{\stackrel{\mathrm{MO}}{\longrightarrow}-\mathrm{CH}_{2} \mathrm{CH}_{2} \mathrm{CCH}_{3}}
\end{aligned}
$$

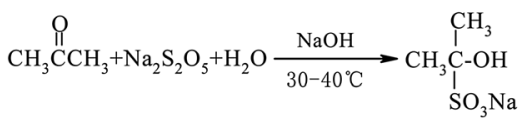

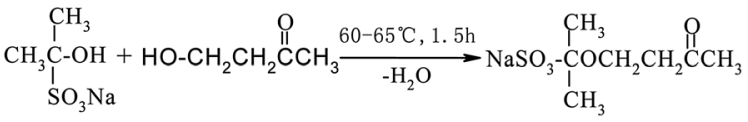

Fig. 1 Reaction routes of sulfonated acetone-formaldehyde.

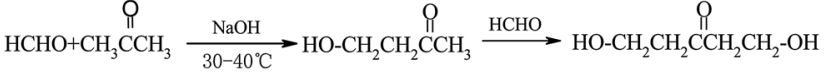

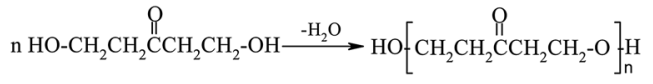

Fig. $2 \beta$-Hydrox-ketone condensation reaction.

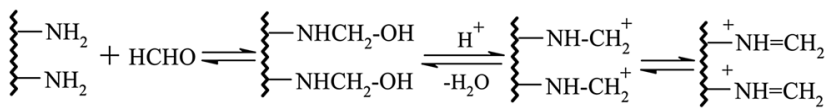

Fig. 3 Cross-linking gelatin with formaldehyde reaction.

ketone, forming dihydroxy compound. Dehydration-condensation reaction would take place between those dihydroxy compounds, and then the polycondensate with large molecular weight would be produced, as shown in Fig. 2. Those polycondensate enhance the stereo-hindrance effect of the grafted reaction with gelatin, which is adverse to the grafted reaction.

In the environment of $\mathrm{pH}=6.5$, through the Mannich reaction of gelatin, formaldehyde and sulfonated acetoneformaldehyde, GAFS can be synthesized. The reaction can be divided into two steps: firstly, through the condensation reaction between formaldehyde and side chain of gelatin, amido cation can be formed, and then the amido cation translate into azomethine cation, as shown in Fig. 3; next, azomethine cation reacts with ketone contain $\alpha$ active hydrogen, by which sulfoacid basic groups can be introduced into the gelatin molecules, forming GAFS, as shown in Fig. 4.

The gel filtration chromatography (GPC) of the GAFS showed a broad peak, as shown in Fig. 5. The molecular weights of the GAFS, such as number-average molecular weight $\left(M_{\mathrm{n}}\right)$, weight- average molecular weight $\left(M_{\mathrm{w}}\right)$, peak molecular weight $\left(M_{\mathrm{p}}\right)$ and polydispersity index (PDI, ratio between $M_{\mathrm{n}}$ and $M_{\mathrm{w}}$ ) are shown in Table 1.

The FTIR spectra comparison of GAFS and gelatin are depicted in Fig. 6. As can be seen, two strong absorption peaks are located at $1190 \mathrm{~cm}^{-1}$ and $1046 \mathrm{~cm}^{-1}$ within the FTIR spectra of GAFS. The peak at $1190 \mathrm{~cm}^{-1}$ are characteristic absorption peak of sulphonate while the peak at $1406 \mathrm{~cm}^{-1}$ are characteristic adsorption of asymmetric $\mathrm{C}-\mathrm{O}$ stretch vibration peak of ether bond $\mathrm{C}-\mathrm{O}-\mathrm{C}$. The $\mathrm{C}-\mathrm{N}$ stretching vibration peak of primary amine groups on gelatin is located at $1537 \mathrm{~cm}^{-1}$, while the $\mathrm{C}-\mathrm{N}$ stretching vibration peak appear at $1550 \mathrm{~cm}^{-1}$ within the FTIR spectra of GAFS. This can be attributable to the fact that, after the grafting reaction, the primary amines in gelatin become secondary amines, resulting in the shifting of $\mathrm{C}-\mathrm{N}$ stretching vibration peak to higher wave numbers. There are characteristic absorption peaks of peptide I and peptide II on the FTIR spectra of GAFS, demonstrating that the main structure of the gelatin is not changed.

\section{Adsorption properties}

The dispersion performance of dispersant is based on the adsorption of dispersant on cement particles. The adsorption isotherms of GAFS on class-G oil well cement particles at $15^{\circ} \mathrm{C}$, $30{ }^{\circ} \mathrm{C}, 45^{\circ} \mathrm{C}$ and $60{ }^{\circ} \mathrm{C}$, which are equal to $288 \mathrm{~K}, 303 \mathrm{~K}, 318 \mathrm{~K}$ and $333 \mathrm{~K}$ under the temperatures standard of thermodynamics, are shown in Fig. 7.

It can be seen that, the adsorption capacities of GAFS increase as the equilibrium concentration $\left(c_{\mathrm{e}}\right)$ increasing regardless of the temperatures. At the beginning, the increase of adsorption capacities of GAFS are rapid. Then the adsorption capacities increase slowly and tend to be constant in the end. There is a single adsorption plateau in every adsorption isotherm, which indicate that the adsorption of GAFS on class$\mathrm{G}$ oil well cement particles is monolayer adsorption. The adsorption capacity of GAFS decreases as the temperature increasing, and this observation demonstrates that the adsorption of GAFS would be affected by the high-temperature to a certain extent.

The Langmuir isotherm and Freundlich isotherm are two most often used isotherms. ${ }^{\mathbf{1 5 , 1 6}}$ The Langmuir equation (eqn (4)) is based on a theoretical model which assumes monomolecular layer adsorption without mutual interaction between adsorbed molecules.

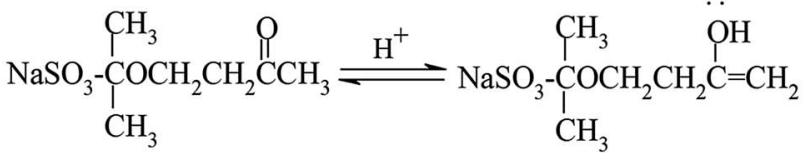

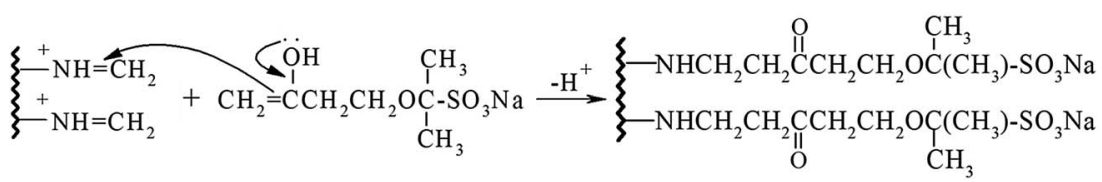

Fig. 4 Mechanism of gelatin grafted reaction. 


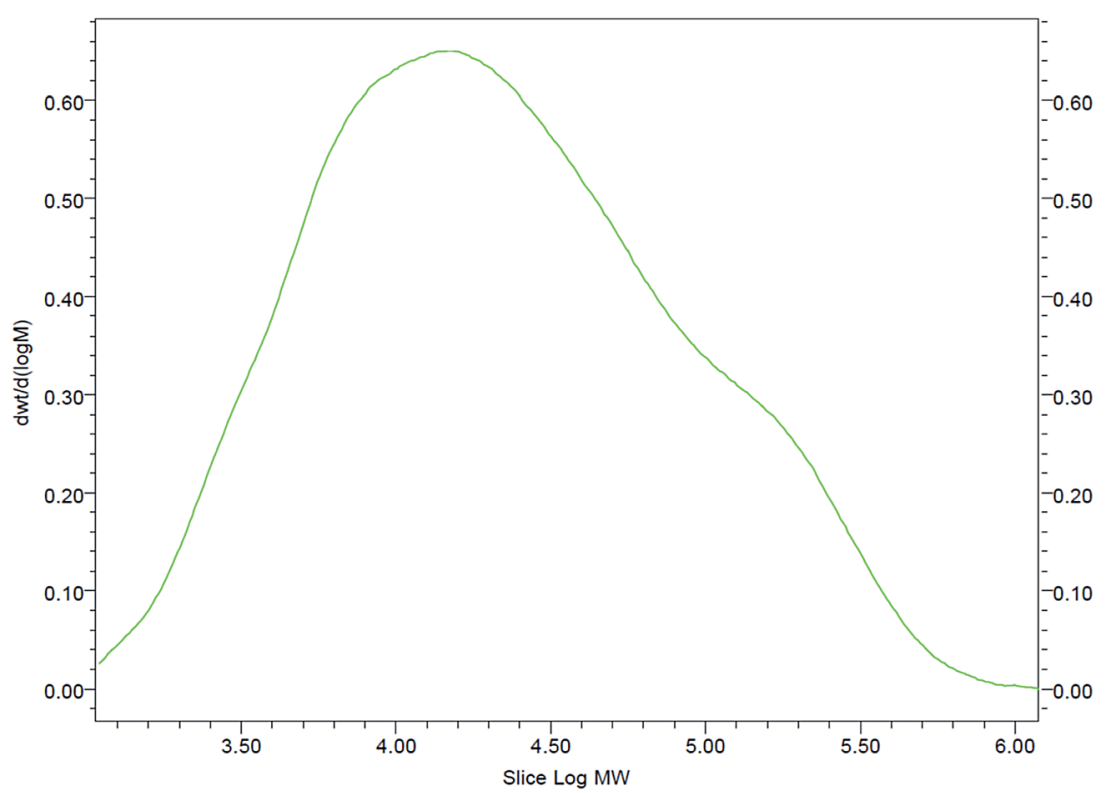

Fig. 5 Molecular weight measurement of GAFS.

Table 1 Molecular weight of the synthesized GAFS

\begin{tabular}{lllll}
\hline $\begin{array}{l}\text { Molecular } \\
\text { weight }\end{array}$ & $M_{\mathrm{n}} / \mathrm{g} \mathrm{mol}^{-1}$ & $M_{\mathrm{w}} / \mathrm{g} \mathrm{mol}^{-1}$ & $M_{\mathrm{p}} / \mathrm{g} \mathrm{mol}^{-1}$ & PDI \\
\hline Value & 10243 & 52261 & 15224 & 5.1
\end{tabular}

$$
\frac{Q_{\mathrm{e}}}{Q_{\mathrm{MAX}}}=\frac{b c_{\mathrm{e}}}{1+b c_{\mathrm{e}}}
$$

where $Q_{\mathrm{e}}$ is the adsorption capacity at the adsorption equilibrium concentration $\left(\mathrm{mg} \mathrm{g}^{-1}\right) ; Q_{\mathrm{MAX}}$ is the saturated capacity $(\mathrm{mg}$ $\left.\mathrm{g}^{-1}\right) ; b$ is the Langmuir adsorption coefficient $\left(\mathrm{L} \mathrm{mg}^{-1}\right) ; c_{\mathrm{e}}$ is the adsorption equilibrium concentration $\left(\mathrm{mg} \mathrm{L}^{-1}\right)$.

A linearized form of eqn (4) can be written as:

$$
\frac{c_{\mathrm{e}}}{Q_{\mathrm{MAX}}}=c_{\mathrm{e}} / Q_{\mathrm{e}}+1 / b Q_{\mathrm{e}}
$$

The Freundlich equation (eqn (6)) can be used to describe the adsorption behavior of monomolecular layers as well as that

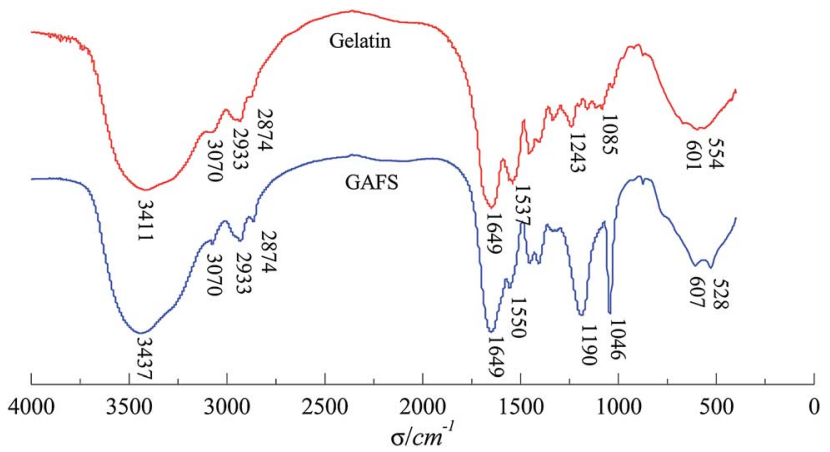

Fig. 6 FTIR spectra of the GAFS dispersant and gelatin. of multimolecular layers. Its linearized form (eqn (7)) can be written as:

$$
\begin{gathered}
Q_{\mathrm{MAX}}=K_{\mathrm{f}}+c_{\mathrm{e}}^{1 / n} \\
\ln Q_{\mathrm{MAX}}=(1 / n) \ln c_{\mathrm{e}}+\ln K_{\mathrm{f}}
\end{gathered}
$$

where $n$ is the parameter which relates to the adsorption strength; $K_{\mathrm{f}}$ is the parameter which relates to the adsorption capacity $\left(\left(\mathrm{L} \mathrm{mg}^{-1}\right)^{1 / n}\right)$.

The adsorption isotherms of GAFS are fitted according Langmuir equation and Freundlich equation, and the fitted curves are shown in Fig. 8.

As seen in Fig. 8, the fitting similarity between Langmuir equation and the adsorption isotherms of GAFS on class-G oil well cement particles at different temperature are high, and the

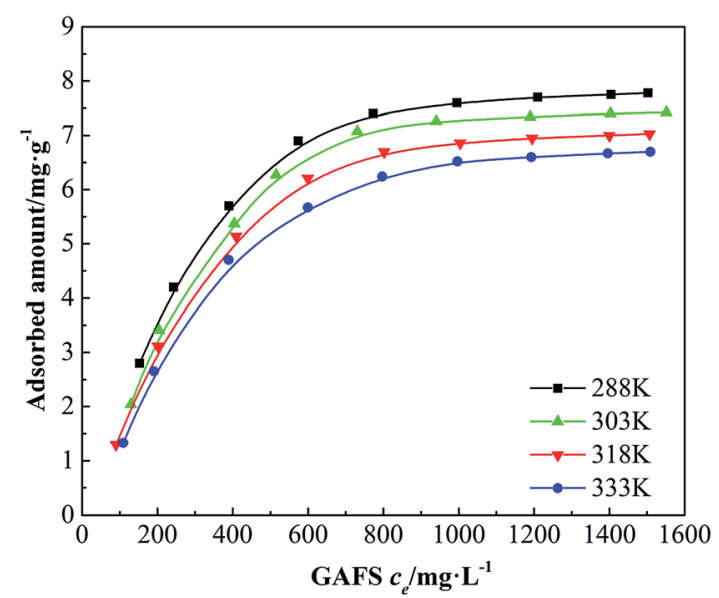

Fig. 7 Adsorption isotherm for GAFS dispersant on class-G oil well cement. 

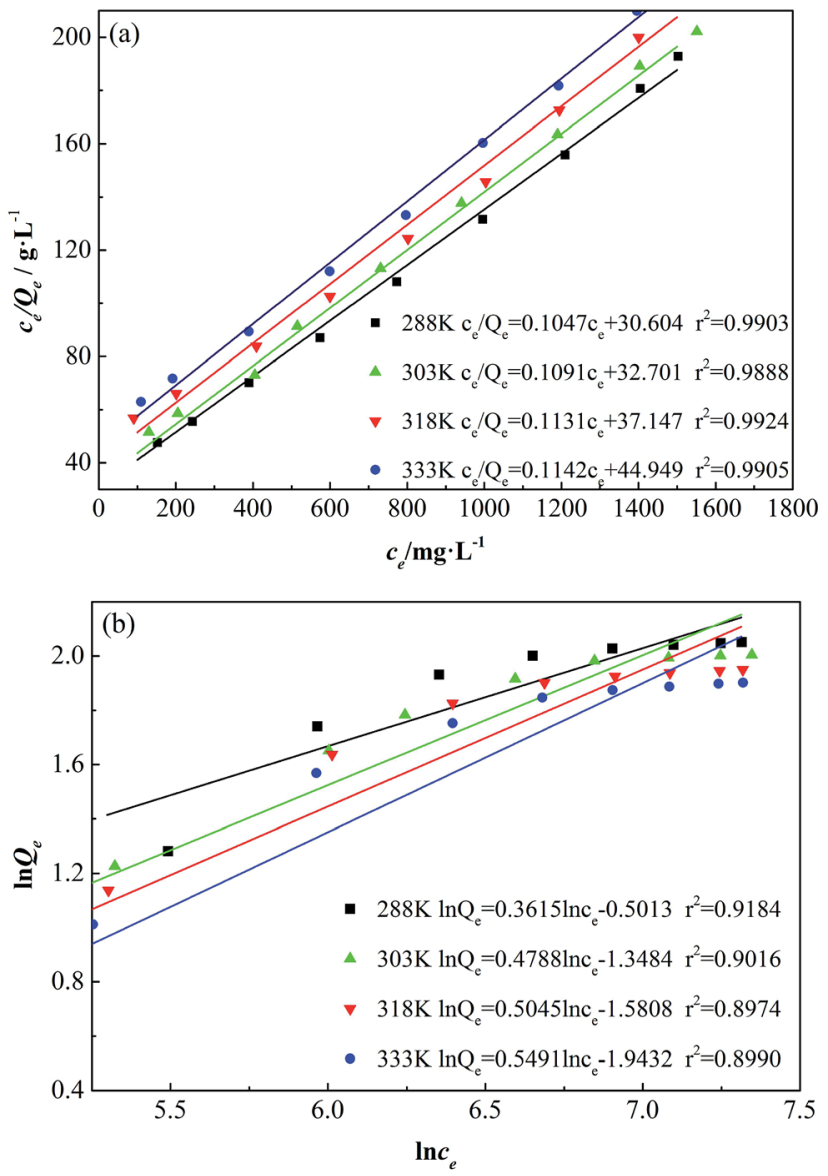

Fig. 8 Langmuir adsorption isotherm (a) and Freundlich adsorption isotherm (b) for GAFS at different temperatures.

correlation coefficients are over 0.99 , which are high than Freundlich equation. Consequently, the Langmuir equation can describe the adsorption of GAFS better, which indicate that the adsorption mainly occurs on the active location of the cement particles surface.

The main parameters related to the adsorption, including $Q_{\mathrm{MAX}}, b, n, K_{\mathrm{f}}$, can be calculated according to Fig. 8, and the results is shown in Table 2.

Both the Langmuir adsorption coefficient $b$ and the adsorption equilibrium constant $K_{\mathrm{f}}$ can be used to measure the

Table 2 Characteristic parameter of Langmuir and Freundlich adsorption isotherm for dispersants cement particle at different temperatures

\begin{tabular}{|c|c|c|c|c|}
\hline \multirow[b]{2}{*}{ Temperature/K } & \multicolumn{2}{|c|}{$\begin{array}{l}\text { Fitted by Langmuir } \\
\text { equation }\end{array}$} & \multicolumn{2}{|c|}{$\begin{array}{l}\text { Fitted by Freundlich } \\
\text { equation }\end{array}$} \\
\hline & $\begin{array}{l}Q_{\mathrm{MAX}} / \\
\mathrm{mg} \mathrm{g}^{-1}\end{array}$ & $\begin{array}{l}b \times 10^{-3} / \\
\mathrm{L} \mathrm{mg}^{-1}\end{array}$ & $n$ & $\begin{array}{l}K_{\mathrm{f}} / \mathrm{mg} \mathrm{g}^{-1} \\
\left(\mathrm{~L} \mathrm{mg}^{-1}\right)^{1 / n}\end{array}$ \\
\hline 288 & 9.551 & 3.421 & 2.766 & 0.6057 \\
\hline 303 & 9.158 & 3.339 & 2.089 & 0.260 \\
\hline 318 & 8.842 & 3.045 & 1.982 & 0.207 \\
\hline 333 & 8.772 & 2.536 & 1.821 & 0.143 \\
\hline
\end{tabular}

desorption trend of adsorbent from the adsorbate. There is a proportional relation between $b$ and $K_{\mathrm{f}}$, and a higher value of $b$ and $K_{\mathrm{f}}$ indicate a lower desorption trend, so that the dispersant with higher $b$ and $K_{\mathrm{f}}$ means better dispersing performance. ${ }^{17}$ In addition, the saturated capacity of GAFS on cement particles is high. That can be attributable to the fact that, there is no large steric hindrance side chain on GAFS molecule, and the hydrophobic groups of GAFS molecule are small, resulting in a large adsorption amount of GAFS on cement particles. With temperature increasing, the adsorbability of GAFS decline slightly.

The initial concentration of dispersion has significant effect on the adsorption strength. The essential characteristics of the adsorbability can be expressed by a dimensionless constant called the separation factor $R_{\mathrm{L}}$ (eqn (8)), which was first defined by Vermeulen et al. ${ }^{18}$ The curves are given by plotting $R_{\mathrm{L}}$ versus initial concentration $\left(c_{0}\right)$ of GAFS in Fig. 9.

$$
R_{\mathrm{L}}=1 /\left(1+b c_{\mathrm{o}}\right)
$$

The value of $R_{\mathrm{L}}$ indicates the adsorption property of adsorbate. When $R_{\mathrm{L}}>1$, it is unfavorable for adsorption; when $R_{\mathrm{L}}=1$, adsorption process is in equilibrium (linear adsorption); when $0<R_{\mathrm{L}}<1$, it is favorable for the adsorption, and the adsorption strength can be either extremely high $\left(0<R_{\mathrm{L}}<0.1\right)$, high $(0.1<$ $\left.R_{\mathrm{L}}<0.5\right)$, medium $\left(0.5<R_{\mathrm{L}}<0.9\right)$ or lower $\left(0.9<R_{\mathrm{L}}<1\right)$; when $R_{\mathrm{L}}$ $=0$, it is irreversible adsorption. ${ }^{18}$

As shown in Fig. 9, under different temperatures, $R_{\mathrm{L}}$ decreases with initial concentration of GAFS increasing and tends to be constant at last. The $R_{\mathrm{L}}$ is in the range of 0.1-0.9 and the minimum value of $R_{\mathrm{L}}$ is close to 0.1 , which indicates that it is favorable for the adsorption of GAFS and the adsorption strength between GAFS and cement particles is high. Set $R_{\mathrm{L}}=$ 0.5 (the horizontal line in Fig. 9), and the difference between corresponding initial concentrations $\left(c_{\mathrm{o}}\right)$ on different temperature lines is not great. This observation demonstrates that the adsorption strength is less affected by temperature.

The tendency, degree and driving force of adsorption process can be clarified by adsorption thermodynamics analysis, which

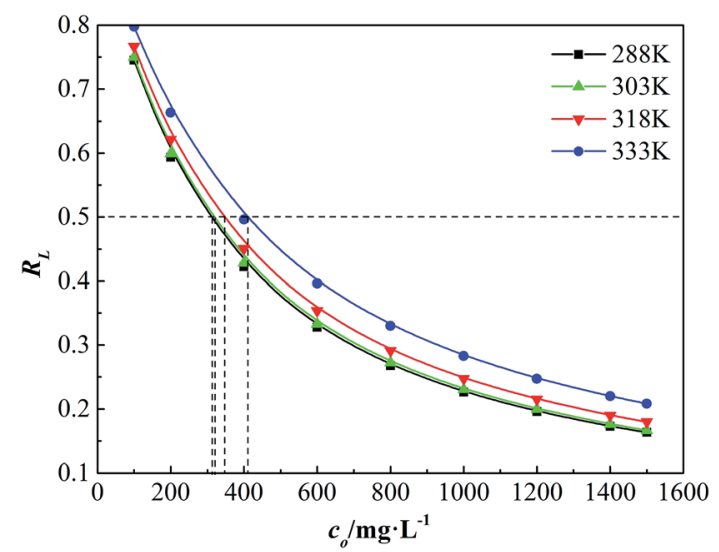

Fig. $9 R_{\mathrm{L}}-c_{\mathrm{o}}$ curve at different temperatures. 


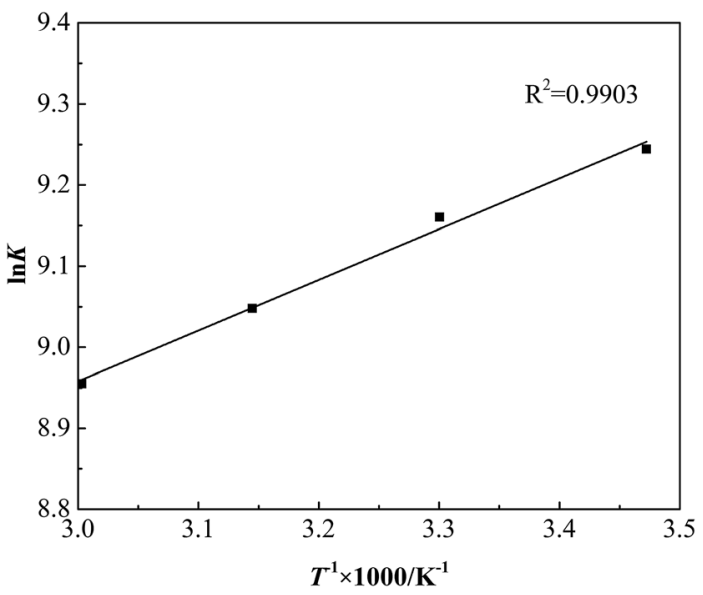

Fig. $10 \ln K-T^{-1}$ curve.

is significant in the study of adsorption properties and adsorption mechanism. The thermodynamic constant $K$ and Gibbs free energy $\Delta G$ can be calculated by weight-average molecular weight $M_{\mathrm{w}}$ and Langmuir adsorption coefficient $b$ according to eqn (9) and (10). ${ }^{19}$ The straight line is given by plotting $\ln K$ versus $1 / T$ in Fig. 10.

$$
\begin{gathered}
K=M_{\mathrm{w}} \times 55.6 b \\
\Delta G=-R T \ln K
\end{gathered}
$$

The adsorption enthalpy $\Delta G$ can be calculated by the slope and intercept of the straight line according to eqn (11), and the adsorption entropy $\Delta S$ can be calculated according to eqn (12). The results are listed in Table 3 .

$$
\begin{gathered}
-\Delta H / R T+\Delta S / R=\ln K \\
(\Delta H-\Delta G) / T=\Delta S
\end{gathered}
$$

As shown in Table 3, during the adsorption process of GAFS onto cement particle surface, the Gibbs free energy $\Delta G$ is negative, which indicates that the adsorption of GAFS is spontaneous process. The adsorption enthalpy $\Delta H<0$, and the $|\Delta H|$ is much less than $40 \mathrm{~kJ} \mathrm{~mol}^{-1}$, so it can be determined that there is no chemical bond and coordinate bond generated and the adsorption of GAFS should be physical adsorption..$^{20}$ The adsorption entropy $\Delta S>0$, meaning that the randomness of

Table 3 Determination result of thermodynamics

\begin{tabular}{lllll}
\hline & & $\begin{array}{l}\Delta G / \\
\mathrm{kJ} \mathrm{mol}\end{array}$ & $\begin{array}{l}\Delta H / \\
\mathrm{kJ} \mathrm{mol}^{-1}\end{array}$ & $\begin{array}{l}\Delta S / \\
\mathrm{J} \mathrm{mol}^{-1} \mathrm{~K}^{-1}\end{array}$ \\
\hline 288 & $K$ & & & \\
303 & 9940.79 & -22.04 & -5.20 & 58.47 \\
318 & 9703.18 & -23.12 & -5.20 & 59.16 \\
333 & 8846.91 & -24.03 & -5.20 & 59.20 \\
& 7369.49 & -24.65 & -5.20 & 58.42
\end{tabular}

molecules on the solid liquid interface increases. ${ }^{21}$ In addition, a higher absolute value of $\Delta H$ is unfavorable to the adsorption. ${ }^{22}$ The absolute value of $\Delta H$ in the adsorption of GAFS is lower, so the adsorption stability is high.

The adsorption properties of GAFS can be demonstrated by its adsorption method on cement particle surface: electrostatic attraction occurs between the strong polar anion groups (i.e., $-\mathrm{SO}_{3}{ }^{-}$) of GAFS and cation groups on cement particles surface, and consequently, driven by this force, the GAFS can be tightly adsorbed on the surface of cement particles. Meanwhile, the weak polar groups on the backbone chain of GAFS can also be adsorbed on the cement particles. As a result, the adsorption method of GAFS on cement particles surface is physical adsorption and its adsorption strength is high. The adsorbent layer thickness of GAFS on cement particles surface was tested, and it is only $2.4 \mathrm{~nm}$. Combining with the above analysis, it can be demonstrated that, the GAFS molecules lie flat on the cement particles surface and generate diffused double layer, as shown in Fig. 11.

\section{Mechanisms}

As shown in Fig. 12, the surface charge state can be changed with the variation of GAFS dosage. When the dosage of GAFS is 0 , the zeta potential of cement particles is positive and its absolute value is small. The positive zeta potential is due to the cation groups such as $\mathrm{Ca}^{2+}$ on cement surfaces. With the dosage of GAFS increasing, the zeta potential sharply reduces and turns into negative. It is due to the fact that the anion groups $-\mathrm{SO}_{3}{ }^{-}$of GAFS is adsorbed on the cation groups and changes the surface charge state. When the dosage of GAFS is in the range of 0.3$0.5 \%$, with the increase of GAFS dosage, the zeta potential of cement suspension system decreases slowly. When the dosage of GAFS reaches $0.5 \%$, the zeta potential drops to the lowest state $-30.57 \mathrm{mV}$. This shows that the sulphonate anion groups and the free groups on the main chain of GAFS molecules can effectively increase the zeta potential (absolute value) of the cement particles.

Dispersion stability of cement slurry mainly depends on the Van der Waals' force, electrostatic repulsion and sterichindrance effect caused by polymer adsorption layer. ${ }^{23-25}$ The electrostatic repulsion potential energy $\left(V_{\text {elect }}\right)$ of same-diameter

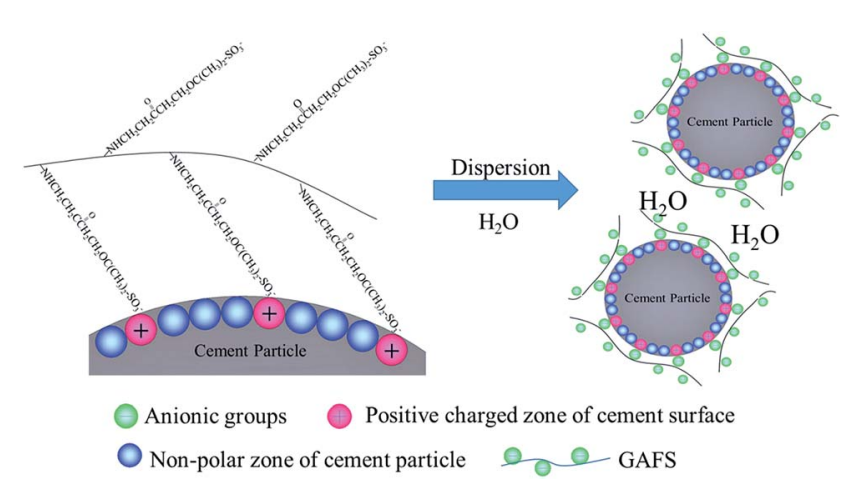

Fig. 11 The dispersion mechanism of GAFS with the cement. 


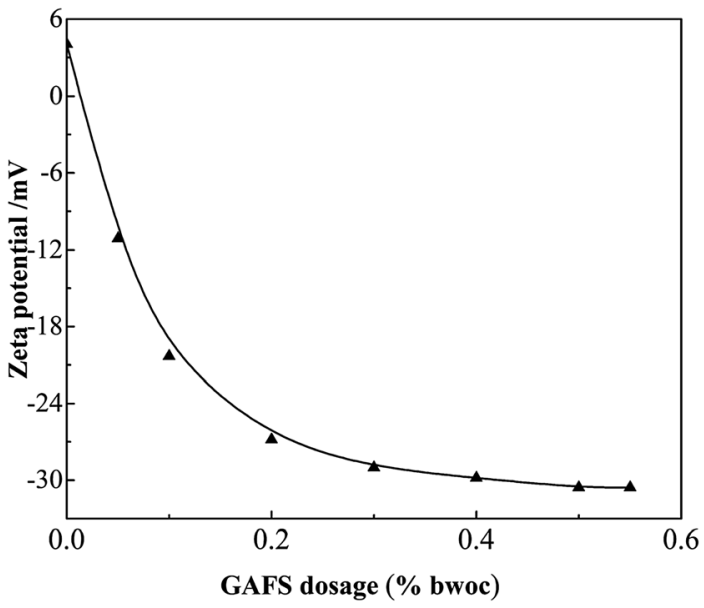

Fig. 12 Variation of zeta potential of cement slurry containing GAFS dispersant with varying dosages.

and same surface-charge spheroidal particles with macromolecule adsorbed on can be calculated by eqn (13). ${ }^{26}$

$$
V_{\text {elect }}=\pi a \varepsilon_{\mathrm{o}} \varepsilon \psi^{2}\left(\frac{k_{\mathrm{B}} T}{e v}\right)^{2}\left[\ln \left(\frac{1+\mathrm{e}^{-k(h-2 \delta)}}{1-\mathrm{e}^{-k(h-2 \delta)}}\right)+\ln \left(1-\mathrm{e}^{-2 k(h-2 \delta)}\right)\right]
$$

where $\varepsilon_{\mathrm{o}} \varepsilon$ is the permittivity of medium, and $\varepsilon_{\mathrm{o}} \varepsilon=7.172 \times 10^{-10}$ $\mathrm{J} \mathrm{K}^{-1} ; \psi$ is the static electric potential of particle surface; $e$ is the electron charge and $e=1.602 \times 10^{-19} \mathrm{C} ; v$ is ion electricity price; $k_{\mathrm{B}}$ is the Boltzmann constant and $k_{\mathrm{B}}=1.38 \times 10^{-23} \mathrm{~J} \mathrm{~K}^{-1}$; $T$ is the degree kelvin ( $298 \mathrm{~K}) ; \delta$ is the adsorbent layer thickness; $k$ is Debye-Hukel constant, which is correlation with the ionic strength of aqueous solution.

The Van der Waals' potential energy $\left(V_{\mathrm{vdw}}\right)$ of spheroidal particles with same diameter and same surface charge can be calculated by eqn $(14) .^{27}$

$$
V_{\mathrm{vdw}}=-\frac{A}{6}\left[\frac{2 a^{2}}{4 a h+h^{2}}+\frac{2 a^{2}}{4 a^{2}+4 a h+h^{2}}+\ln \left(\frac{4 a h+h^{2}}{4 a^{2}+4 a h+h^{2}}\right)\right]
$$

where $A$ is Hamaker constant, and the Hamaker constant of cement is $1.7 \times 10^{-21} \mathrm{~J}$; $a$ is the particle radius; $h$ is the interparticle distance.

In the aqueous solution suspension system, the dispersing performance of dispersion is determined by total potential energy $\left(V_{\mathrm{T}}\right)$. For the cement slurry dispersed by GAFS, the electrostatic repulsion is the main factor affecting dispersing performance, while the steric-hindrance effect functions less. So the total potential energy can be calculated by eqn (15). The adsorption quantity $Q$, zeta potential and adsorbent layer thickness aforementioned are listed in Table 4.

$$
V_{\mathrm{T}}=V_{\mathrm{vdw}}+V_{\text {elect }}
$$

The calculated total potential energy for cement slurry dispersed by GAFS at $25{ }^{\circ} \mathrm{C}$ is shown in Fig. 13. GAFS works by adsorbing on the cement particles and forming strong
Table 4 Adsorption properties of cement slurry with GAFS

\begin{tabular}{llll}
\hline Temperature $/ \mathrm{K}$ & $Q / \mathrm{mg} \mathrm{g}^{-1}$ & Zeta potential $/ \mathrm{mV}$ & Adsorbent layer $/ \mathrm{nm}$ \\
\hline 298 & 7.78 & -30.57 & 2.4
\end{tabular}

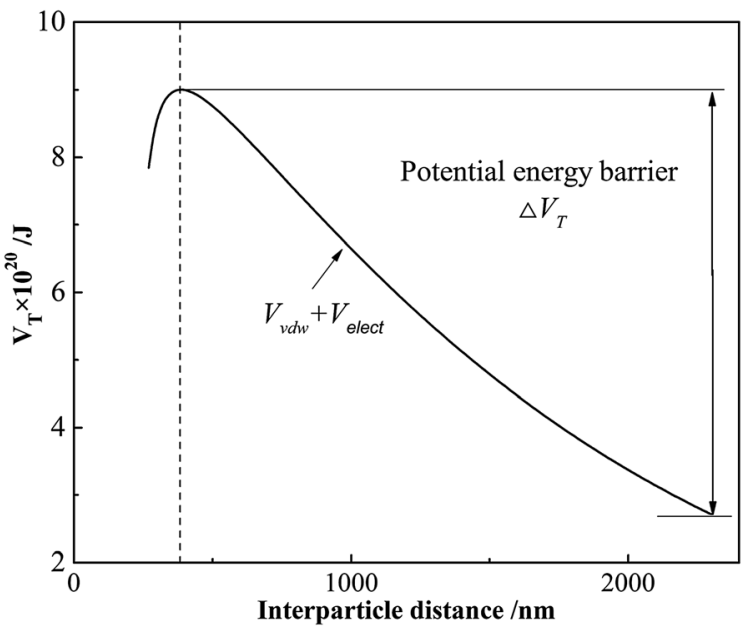

Fig. 13 The calculated total potential energy for cement slurry.

electrostatic forces, which would generate a great potential energy barrier (i.e., $\Delta V_{\mathrm{T}}$ in Fig. 13). Generally, the potential energy barrier is higher than kinetic energy of cement particles driven by the Brownian motion so that the cement particle can
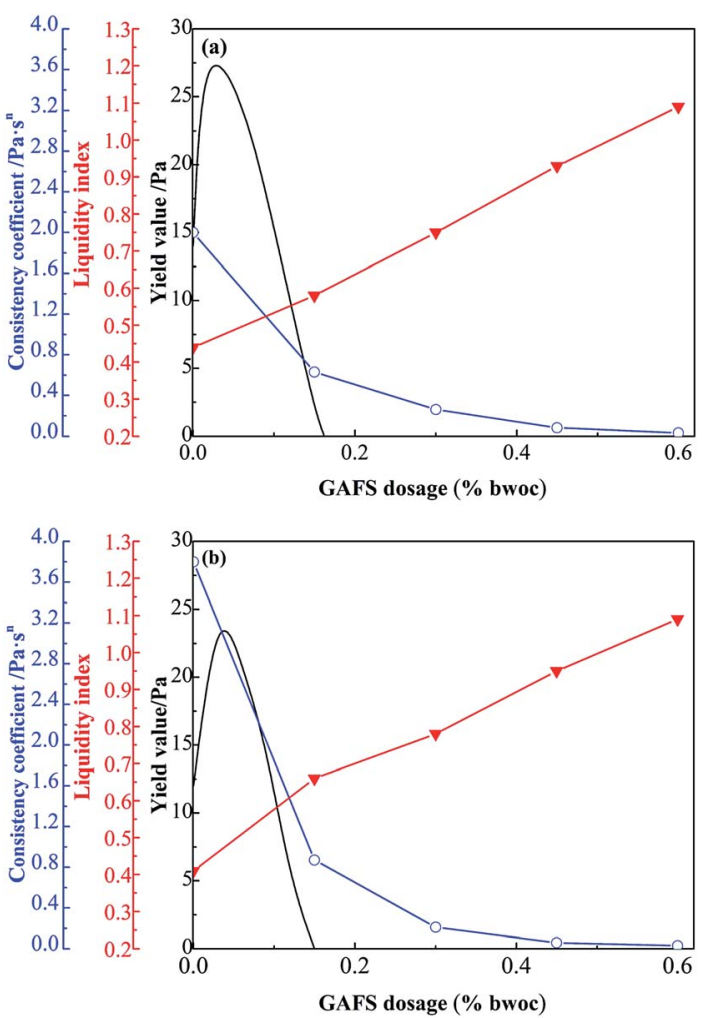

Fig. 14 Variation of properties of cement slurry containing GAFS with varied dosages at $15^{\circ} \mathrm{C}(\mathrm{a})$ and $60^{\circ} \mathrm{C}(\mathrm{b})$. 


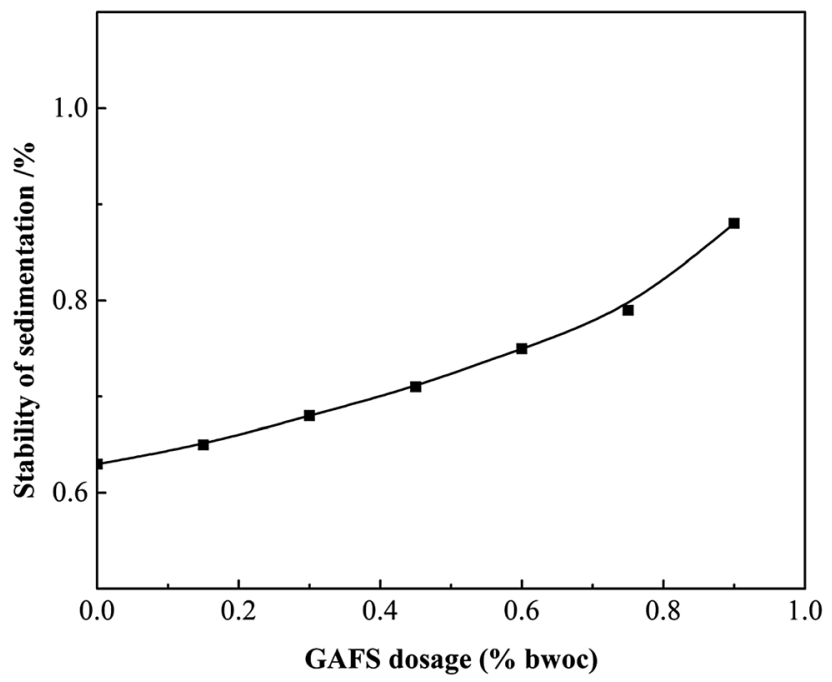

Fig. 15 Variation of properties of cement slurry containing GAFS with varied dosages.

hardly "climb over" it. Consequently, the cement particles are prevented from closing to others and the liquidity can be increased. Potential energy barrier reaches the maximum when the interparticle distance between cement particles is $390 \mathrm{~nm}$. When the cement particles are within a short interparticle distance, the steric-hindrance effect cannot be ignored. The steric-hindrance effect would get stronger with the interparticle distance getting shorter. In this case, cement slurry can keep an excellent dispersion stability by the co-action of Van der Waals' force, electrostatic repulsion and steric-hindrance effect.

\section{Performances}

Rheology property of cement slurry with different dosage of GAFS was tested at $15^{\circ} \mathrm{C}$ and $60^{\circ} \mathrm{C}$, and the results are shown in Fig. 14. As can be seen, the relation curve about the rheological property of cement slurry with the variation of GAFS dosage, the liquidity index $n$ of cement slurry increases gradually with the dosages of GAF increasing, while the consistency coefficient $K$ decreases gradually. At $15{ }^{\circ} \mathrm{C}$, when the dosage of GAFS reaches $0.5 \%$ bwoc, the $n$ of cement slurry increases to 0.93 and the $K$ decreases to 0.08 , which indicates that the mobility of cement slurry is good; furthermore, the fluidity property of cement slurry can also reach an excellent mobility with $0.5 \%$ bwoc GAFS, at $60^{\circ} \mathrm{C}$. This indicates that GAFS has effective dispersing effect, which can significantly improve rheological property of cement slurry and reduce the viscosity of the cement slurry.

There is usually existing interaction force between cement particles, and due to that, the cement slurry presents spacing network structure under static condition. This kind of structure can block the flow of cement slurry unless the shear force is high enough (higher than the yield value) to break the structure. As can be seen in Fig. 14, the relation curve about the yield value of cement slurry with the variation of GAFS dosage, yield value increases with the increase of GAFS and then rapidly reduces to zero. This is because that, under the condition of low GAFS dosage, excess positive charge exists on the cement particle surfaces and that would inhibit the interaction force between cement particles. When the zeta potential reduces to 0 , interaction force between cement particles reaches the maximum, so as the yield value of cement slurry. At a higher GAFS dosage, cement particles surfaces are completely covered by the GAFS so that zeta potential reaches a larger value and yield value reduced to zero under the effect of electrostatic repulsion.

The static stability of cement slurry with GAFS was tested and shown in Fig. 15. As can be seen, the percentage of density difference between the top and the bottom segment is less than $0.8 \%$ with the dosage of GAFS less than $0.8 \%$ bwoc, which meets the demand of cementing engineering. As water-soluble polymer, GAFS can increase the viscosity of water phase to a certain degree and it would relieve the sedimentation of cement slurry.

Enough compressive strength is necessary for cement sheath to withstand the high compression from cement casing and formation, playing a necessary role in supporting the casing. The cement can react with water, namely hydration reaction,

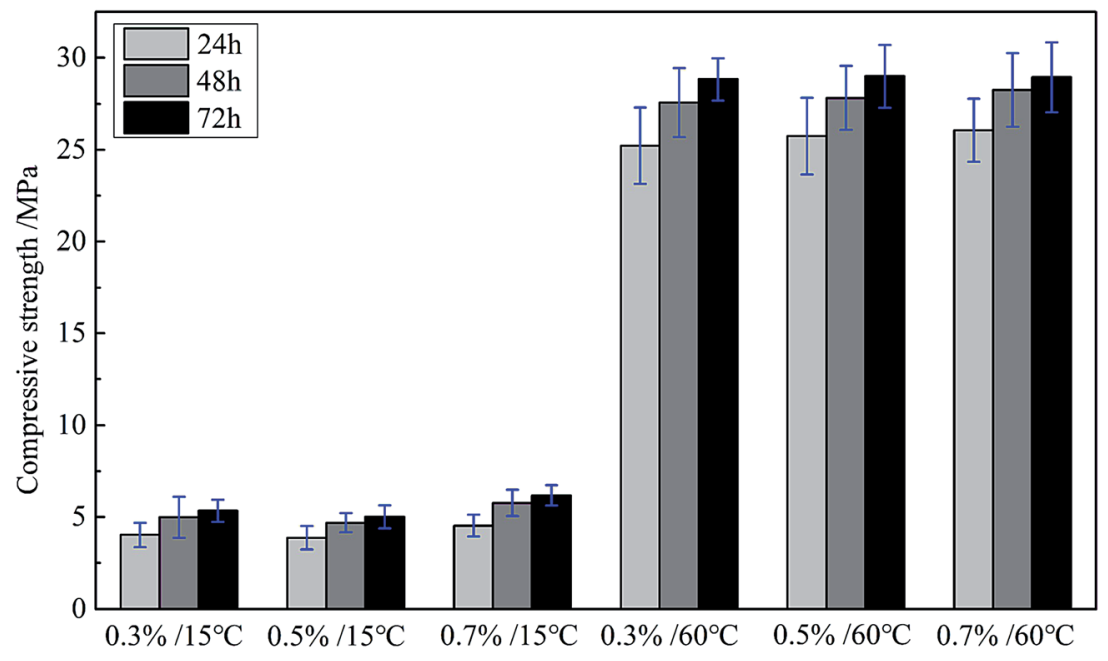

Fig. 16 Compressive strength of cement samples. 


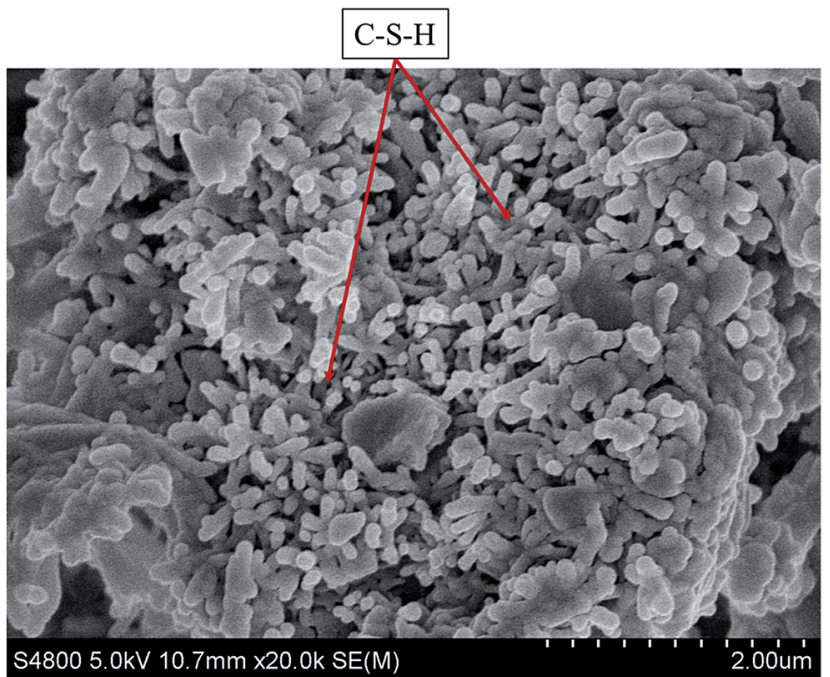

Fig. 17 The microstructure of cement matrix with GAFS after curing for $24 \mathrm{~h}$.

and the fiber-shape calcium silicate hydrate (CSH gel), formed during the hydration reaction of cement slurry, can gradually fill the whole space and interweave together into a tight network, which densify the matrix and compromise the compressive strength. But, as mentioned before, the dispersant can be adsorbed on the cement particles and cover the surface, which would block the contact between cement and water. Consequently, the hydration reaction rate would be influenced to some extent. So the effect of adding the GAFS dispersant on the compressive strength of class-G cement was investigate, shown in Fig. 16.

As can be seen, the addition of GAFS can hardly cause any influence to the compressive strength of cement matrix, no matter at $15{ }^{\circ} \mathrm{C}$ or $60{ }^{\circ} \mathrm{C}$. Compressive strength of all the samples presents a normal growth with the curing time increasing. This is due to that, the adsorption of GAFS on cement particles is physical adsorption, and there is no chemical reaction between GAFS and cement particles. Thus, the chemical properties of the cement would not be influenced by GAFS, and the cement particles are more inclined to react with water to form more stable chemical bonds instead of electrostatic adsorption with GAFS.

Through the SEM, the micro structure of cement matrix with GAFS $\left(0.7 \%\right.$ bwoc, cured for $\left.24 \mathrm{~h}, 60{ }^{\circ} \mathrm{C}\right)$ was presented. As shown in Fig. 17, there are lots of CSH gels formed by hydration reaction and the dispersants adsorb only in very small amounts on $\mathrm{C}-\mathrm{S}-\mathrm{H}$. So these $\mathrm{CSH}$ gels are interwove with others and the network formed by CSH gels can be tight enough.

\section{Conclusions}

(1) Sulphonated bodies is introduced onto the side chain of gelatin molecules by Mannich aminomethylation reaction, and though that, a novel oil-well cement dispersant, GAFS is synthesized. The main chain of GAFS is a kind protein substance formed by various amino acids which is mutually connected by peptide bond. So GAFS is considered to be biodegradable.

(2) The Langmuir equation can describe the adsorption isotherm of GAFS on class-G oil well cement particles better, which indicate that the adsorption mainly occurs on the active location of the cement particles surface. The adsorption thermodynamics analysis results show that, adsorption of GAFS on cement particles is spontaneous and adsorption strength between GAFS and cement particles is high. The adsorption process is an exothermic process. High-temperature is of no advantage to the adsorption, but the influence of temperature to the adsorption strength of GAFS is slight.

(3) Electrostatic attraction occurs between the strong polar anion groups $\left(-\mathrm{SO}_{3}{ }^{-}\right)$of GAFS and the cation groups on cement surfaces. Driven by this force, the GAFS molecules lie flat on the cement particle surfaces and generate diffused double layer. The zeta potential (negative value) of cement particles is very low $(-30.57 \mathrm{mV})$ because of the diffused double layer, and generates strong electrostatic forces, which would generate a great potential energy barrier. Due to that, combining with the steric hindrance effect generated by GAFS molecules, the GAFS dispersant has excellent dispersion properties.

(4) The adsorption of GAFS on cement particles is physical adsorption, and the chemical property of the cement would not be influenced by GAFS. As a consequent, the GAFS influence the hydration reaction slightly and imposes no retarding effect on the cement.

\section{Acknowledgements}

The authors greatly acknowledge the financial supports from the Natural Science Foundation (Grant No.: 51174226), National Science and Technology Major Project of China (No. 2016ZX05044, No. 2016ZX05020) and Program for Changjiang Scholars and Innovative Research Team in University (IRT_14R58).

\section{References}

1 S. Guo, Y. Bu, H. Liu and X. Guo, The abnormal phenomenon of class $\mathrm{G}$ oil well cement endangering the cementing security in the presence of retarder, Constr. Build. Mater., 2014, 54, 118-122.

2 K. J. Goodwin, Oil well/gas well cement-sheath evaluation, J. Pet. Technol., 1997, 49, 1339-1343.

3 E. B. Nelson and D. Guillot, Well Cementing, 2nd edn, Schlumberger Dowell, Sugar Land, 2006.

4 H. Lou, K. Ji, H. Pang, Y. Deng, X. Qiu, H. Zhang and Z. Xie, Effect of molecular weight of sulphonated acetoneformaldehyde condensate on its adsorption and dispersion properties in cementitious system, Cem. Concr. Res., 2012, 42, 1043-1048.

5 O. Burgos-Montes, M. Palacios, P. Rivilla and F. Puertas, Compatibility between superplasticizer admixtures and cements with mineral additions, Constr. Build. Mater., 2012, 31, 300-309. 
6 A. Peschard, A. Govin, P. Grosseau, B. Guilhot and R. Guyonnet, Effect of polysaccharides on the hydration of cement paste at early ages, Cem. Concr. Res., 2004, 34, 2153-2158.

7 Y. Zhang, X. Kong, Z. Lu, Z. Lu and S. Hou, Effects of the charge characteristics of polycarboxylate superplasticizers on the adsorption and the retardation in cement pastes, Cem. Concr. Res., 2015, 67, 184-196.

8 C. Wang, R. Wang, Y. Bu and R. Cheng, Research development of deepwater cementing technique, J. China Univ. Pet., Ed. Nat. Sci., 2008, 32(1), 77-81.

9 P. Rae, G. D. Lullo and A. B. Ahmad, Towards environmentally-friendly additives for well completion and stimulation operations, Society of Petroleum Engineers, 2001, SPE-68651-MS, pp. 1-9.

10 M. Sadeghi and S. Moradi, Synthesis and chemorheology studies of graft copolymers based on gelatin-graftpoly(sodium acrylate-co-acrylamide), Journal of Basic and Applied Scientific Research, 2012, 2, 752-758.

11 F. L. Mi, Synthesis and characterization of a novel chitosangelatin bioconjugate with fluorescence emission, Biomacromolecules, 2005, 6(2), 975-987.

12 C. M. Wang, R. Z. Meng, F. F. Xiao and R. H. Wang, Synthesis and performance evaluation of a novel biodegradable dispersant for offshore cementing, J. Nat. Gas Sci. Eng., 2017, 38, 582-589.

13 A. Zingg, F. Winnefeld, L. Holzer, J. Pakusch, S. Becker, R. Figi and L. Gauckler, Interaction of polycarboxylatebased superplasticizers with cements containing different C3A amounts, Cem. Concr. Compos., 2009, 31, 153-162.

14 API RP10B-2-2013, Recommended practice for testing well cements, API Publishing Services, Washington, DC.

15 I. Langmuir, The Adsorption of Gases on Plane Surfaces of Glass, Mica and Platinum, J. Am. Chem. Soc., 1918, 40(9), 1361-1403.

16 G. Sreelatha, V. Ageetha, J. Parmar and P. Padmaja, Equilibrium and kinetic studies on reactive dye adsorption using palm shell powder (an agrowaste) and chitosan, $J$. Chem. Eng. Data, 2011, 56(1), 35-42.

17 A. M. Carmo, L. S. Hundal and M. L. Thompson, Sorption of hydrophobic organic compounds by soil materials: application of unit equivalent Freundlich coefficients, Environ. Sci. Technol., 2000, 34(20), 4363-4369.

18 K. R. Hall, L. C. Eagleton, A. Acrivos and T. Vermeulen, Pore and Solid-Diffusion Kinetics in Fixed-Bed Adsorption under Constant-Pattern Conditions, Ind. Eng. Chem. Fundam., 1966, 5, 212.

19 B. Bai, Y. Wu and R. B. Grigg, Adsorption and desorption kinetics and equilibrium of calcium lignosulfonate on dolomite porous media, J. Phys. Chem. C, 2009, 113(31), 13772-13779.

20 B. V. Open, W. Kordel and W. Klein, Sorption of nonplus and polar compounds to soils: processes, measurement and experience with the applicability of the modified OECED guideline, Chemosphere, 1991, 22, 285-304.

21 Z. Dong, W. Ding, K. Liu, Z. Zhang, G. Qu and T. Yu, Adsorption Performance of Tetradecyl Aryl sulphonates on Oil Sand from the Daqing Oilfield, Acta. Phys.-Chim. Sin., 2011, 27(12), 2767-2772.

22 Z. Dong, W. Ding, K. Liu, Z. Zhang, G. Qu and T. Yu, Adsorption Performance of Tetradecyl Aryl sulphonates on Oil Sand from the Daqing Oilfield, Acta. Phys.-Chim. Sin., 2011, 27(12), 2767-2772.

23 J. Plank and B. Sachsenhauser, Impact of molecular structure on zeta potential and adsorbed conformation of $\alpha$-allyl- $\omega$-methoxypolyethylene glycol-maleic anhydride superplasticizers, J. Adv. Concr. Technol., 2006, 4(2), 233239.

24 E. Sakai and M. Daimon, Mechanisms of Superplasticizers, Am Ceram Soc., USA, 1995, pp. 91-111.

25 F. Winnefeld, S. Becer and J. Pakusch, Effects of the molecular architecture of comb-shaped superplasticizers on their performance in cementitious systems, Cem. Concr. Compos., 2007, 29(2), 251-262.

26 W. B. Russel, D. A. Saville and W. R. Schowalter, Colloidal Dispersions, 1st edn, Cambridge University Press, UK, 1989, pp. 129-160.

27 K. Yoshioka, E. Sakai, M. Daimon and A. Kitahara, Role of steric hindrance in the performance of superplasticizer for concrete, J. Am. Ceram. Soc., 1997, 80, 2667-2671. 